\title{
The Dynamics of Dignity at Work
}

\section{Paul Thompson and Kirsty Newsome}

In A Gedenkschrift to Randy Hodson: Working with Dignity, pp. 79-100. Emerald Group Publishing Limited, 2016, pp: 79-100.

For an international audience Randy Hodson's contributions were around the twin themes of dignity and resistance. We refer to them as twinned because they were conceptualised and operationalised as if not exactly inseparable, then at least intimately connected. Resistance is conceived primarily as a response to the absence of or threats to dignity. Our engagement with Hodson's work came through an attempt to explore its usefulness in helping understand the experience of low skill and low paid factory workers at the very undignified end of supermarket supply chains in the UK (Newsome, Thompson and Commander 2008). In this chapter we have expanded that engagement to cover more of the ideas developed by Randy and his co-writers and we have added new evidence of our own from the supply chain study.

At the time of the initial engagement, the idea of dignity was undergoing something of a renaissance theoretically and practically. Labour scholars were picking up the baton (Sayer 2007a, b; Bolton 2007) and perhaps, more significantly, it was emerging as a focal point of policy discourse among employers, unions and government ranging from international debates on 'good work to localised dignity at work codes (see for example, Raynor and Mclvor 2008). Irrespective of whether Hodson's contribution has had any impact on such developments or is purely co-incidental, his conceptual framework has far more analytical purchase because it moves beyond dignity as a relatively free floating concept, merely applied to the economy and work, to consider its relational characteristics.

Hodson's (2001) categories offer an ambitious, comprehensive framework for analysing the objective and subjective conditions that shape dignity at work. Dignity at work is regarded first and foremost as deriving from the purposeful, strategic actions of workers to attain and maintain dignity within work, and management-influenced conditions that destroy or deny it. We will look briefly at each in turn. Dignity is asserted to be the overarching goal of worker behavior (ibiod 60) and within this context, a range of 'alternative behavioural strategies' exist to pursue it. These strategies encompass actions that are normally seen as antithetical: on the one hand resistance and on the other, citizenship. Whereas the former involves the conventional array of behaviours (sabotage, absenteeism, work avoidance) familiar to industrial sociology and labour process theory (LPT), the latter focuses on the tendency to take pride in work accomplishments and 'transform jobs with insufficient meaning into jobs that are more worthy of their personal stature, time and effort' (45). Both are strengthened by other 'meaningful actions' of workers, notably the creation of independent meaning systems and attention to the social climate of the workplace through coworker relations and other aspects of friendship and group solidarity. Whilst such activities are played out in daily work life, they 'may be only tangentially related to management demands and organizational agendas' (18).

Turning to the challenges to dignity, these arise primarily from 'poor organization and coordination of the labour process' (Roscigno, Hodson and Lopez 209: 749). This is framed in terms of chaotic, disorganized and abusive workplaces, which, coupled with overwork and exploitation, are more likely to occur in situations where management has unilateral control over production. A second 
setoff challenges flow from constraints on autonomy and new demands of involvement, occurring where employees have some greater degree of discretion over their work tasks. Indeed the often contradictory demands of enhanced employee involvement are highlighted as providing the opportunity for greater dignity, but simultaneously being open to abuse.

This framework is seen by Hodson as expanding the capacity of social science to 'describe and analyse workers' complex and sometimes contradictory behaviours..' (16),. On that score it succeeds. Under the general heading of 'safeguarding dignity', the categories expand our vocabulary and mapping of worker agency. There are similarities to Ackroyd and Thompson remapping through the concept of organisational misbehaviour. Indeed, this is acknowledged in Roscigno et al paper where it says that the framework is 'Consistent with the emphasis in the organizational misbehaviour literature on bringing worker agency back into theoretical perceptions' $(2009,761)$.

One distinctive aspect of the expanded agency framework is the view that not all 'resistance' is interests-driven or connected explicitly to the effort bargain. For example, a distinction is made between 'interest conflicts' and 'as opposed to broader, status-based processes of social closure'. (Roscigno et al 2009: 748). Elsewhere the argument appears to be that 'safeguarding dignity' is an end in itself, irrespective of competing interests in the employment relationship.: 'rather than such resistance being solely an effort to regain dignity in the face of personal insult and conflict with managers, resistance in such settings may be as much a function of frustration, boredom, and personal stress resulting from organisational chaos'. (Roscigno and Hodson 2004: 34). Furthermore, this requires recognition that horizontal relations 'with peers and customers can also be an important source of incivility and must also be incorporated into the analysis' (Roscigno et al, 2009: 749-50). So for example, gossip, backbiting, and character assassination tyend to flourish in a context of chronic mismanagement (Roscigno and Hodson 2004: 23). In the later work, both forms of conflict - vertical and horizontal - are brought together under the term 'incivilities', defined as 'negative relational aspects of employment with implications for safety, integrity and dignity' (Roscigno et al, 2009: 748).

We are sympathetic to the intent of expanding types and sources of labour agency. As we have observed elsewhere (Thompson and Newsome 2004), second wave LPT became a control, resistance and consent model. Burawoy's (1979) hugely-influential theorisation of consent expanded our vocabulary of worker behaviour and restored a certain kind of agency through a focus on active participation in workplace games and organisational choices. However, the consent concept was elaborated primarily to solve the puzzle, why don't workers resist, or at least resist more often that they do? The insights were large, but the scope of explanation was comparatively small. Also the control and resistance model that underpinned second wave theory and research was largely built on the experiences of large workplaces and well-organised workers. At the end of the supermarket supply chain, we find labour that has limited power resources and low levels of unionisation. 'Resistance', whether expressed through powerful informal job controls or formal, collective action and organisation, doesn't seem to provide an adequate conceptual template for analysing the work and its experiences in forgotten factories. The focus on horizontal relations and the interactional life of a workgoup' (Roscigno et al 2009: 760) has parallels with Ackroyd and Thompson's (1999) concept of misbehaviour through 'irresponsible autonomy' in workgroups, as well as the attention paid to conflicts over identity and symbolic resources. 
Nevertheless, a comparison with LPT also reveals some limitations to the framework and its explanatory powers elaborated by Hodson and his collaborators. The framework is relational, but what are the relations? If LPA is associated with control and resistance, Hodson et al advance what is in essence an abuse/chaos-dignity model, in which all forms of incivility (except sexual harassment) are seen as rooted in organisational chaos (Roscigno et al 2009).

We would highlight three inter-related problems. First, what are the dynamics of the workplace behaviour described? Conventional notions of agency are, in effect, inverted by Hodson. Worker actions to create meaning systems and dignity are presented as the driver, with management actions as the 'challenge' to them. There is an equivalence problem here. Whereas worker actions are 'strategic', it is never clear what drives management action, and whether such action is purposeful, reactive or a reflection of lack of purpose (as in chaotic practices). The four types of 'challenge' lack any coherence as categories - employee involvement could be seen as a variant of responsible autonomy, but abuse is hardly a strategy. In fact, the whole concept of abuse and mismanagement is problematic, at least as a means of understanding the conditions for 'good' and 'bad' work. Abusive and 'poorly managed' (Hodson 2001: 260) workplaces are associated in the book with arbitrary and autocratic power. The implication can only be that normal, rational management and work organisation is not or is unlikely to be an attack on dignity. The overwork category is much circumspect and therefore more useful. Though under-conceptualised (as stress and chronic pressure) and conflated with 'exploitation', as a driver of poor work experience, it is consistent with a growing body of research on work intensification (Green 2001, Burchell et al 2002).

Second, the pursuit of dignity is seen as partially independent of the employment relationship work is an arena in which dignity is sought and contested. Whilst a case could be made that dignity is a goal of worker action, it is dangerous to subsume all other goals within that overarching notion, notably the pursuit of collective interests via the effort bargain. In contrast, the idea that denying dignity could be a driver of managerial behaviour, at least independently of conflicting interests in the employment relationship, lacks credibility. By partially abstracting dignity dynamics from that relationship, Hodson's framework over-estimates the capacity for common interests, for example on citizenship actions (see Hodson 2001: 46). Relatedly, by neglecting and inadequately explaining managerial agency, the analysis under-estimates the structural, market constraints on 'normal' companies to providing good work and dignified employment.

Third, we have no problem with treating resistance behaviours a sub-set of worker agency. Indeed, we would argue that some of the actions designated as such are better thought of as misbehaviours. However, we do have a problem with resistance being incorporated into an overarching category of incivilities, alongside demeaning or derogatory interactions (see Roscigno and Hodson 2009: 748). Incivility is understood as a breach of norms and whilst this does allow for going beyond notions of individual deviance, treating the workplace primarily as a normative order further weakens the idea of capital-labour relations as resting on a structured antagonism.

Our case studies, discussed in the next section, are not the kind of workplace ethnography discussed in Hodson's book or the related articles. These are largely book length ethnographies, many from the labour process tradition, analysed through thematic coding using a combination of qualitative and quantitative methods. However, our cases do provide an opportunity to explore the salience of 
the issues raised and categories utilized Bu Hodson and collaborators, particularly with reference to the dignity debate.

To uncover the experiences of work in supermarket supply chain in the UK this chapter draws on qualitative evidence from a wider research project concerned with exploring labour process change within the grocery supply chain. The primary research question has been concerned with exploring to what extent and in what ways are dominant retailers/customers influencing work, employment and labour-use strategies within supply organisations? In our first engagement with Hodson (Newsome, Thompson and Commander 2009) we explored the dynamics for dignity at work in three food manufacturing companies, highlighted in table 1 below. For this chapter we revisit evidence from the same food manufacturing companies and develop further dimensions of dignity by exploring additional evidence from three retail distribution companies'. The benefit of exploring evidence from both production and distribution organisations is that it enables greater theoretical insights to be gained by positioning the conditions for dignity amongst the articulated relations between production, distribution and exchange.

All of the case-study organisations are located in the UK. The food manufacturing case-studies were selected on the basis of size, ownership, type of customer, nature/quality of product and levels of unionisation. Skin is a large unionised organisation involved in the processing and packaging of fruit and vegetables for a number of the high-end major retailers. Stir-Fry is a large firm with a single-supply agreement with one of the large multiples. Asar is a second-tier supplier which processes fruit and vegetables for the food manufacturing companies most notably the ready-meal producers. Grocery warehousing and distribution performs a critical function within the retail supply chain, the three casestudies were selected on the basis of their third party relationship with the grocery retailers. Each of the organisations operated single-supply agreements with retailers from a regional distribution centres (RDC). The RDC all housed ambient and chilled warehouses and in the case of Manoeuvre an additional frozen warehouse. All of the distribution companies are unionised, albeit with varying degree of union density.. Table one below outlines the case-study organisations.

\begin{tabular}{|c||c|c|c||c|c|c||}
\hline \multicolumn{1}{|c||}{} & \multicolumn{3}{c||}{ Food Processing } & \multicolumn{3}{c||}{ Food Distribution } \\
\cline { 2 - 7 } & Skin & Stir-Fry & Asar & Mirror & Signal & Manoeuvre \\
\hline $\begin{array}{c}\text { Size / No. } \\
\text { of } \\
\text { Employees }\end{array}$ & Large & Medium & Small & Large & Large & Large \\
\hline Ownership & $\begin{array}{c}\text { UK } \\
\text { Private } \\
\text { Ltd }\end{array}$ & $\begin{array}{c}\text { UK } \\
\text { Private } \\
\text { Ltd }\end{array}$ & $\begin{array}{c}\text { UK Private } \\
\text { Ltd }\end{array}$ & MNC & MNC & MNC \\
\hline $\begin{array}{c}\text { Type } \\
\text { of Customer }\end{array}$ & $\begin{array}{c}\text { UK } \\
\text { multiples }\end{array}$ & $\begin{array}{c}\text { Single } \\
\text { multiple }\end{array}$ & $\begin{array}{c}\text { UK } \\
\text { multiples } \\
\text { via 3rd } \\
\text { parties }\end{array}$ & $\begin{array}{c}\text { Single } \\
\text { multiple }\end{array}$ & $\begin{array}{c}\text { Single } \\
\text { multiple }\end{array}$ & $\begin{array}{c}\text { Single } \\
\text { multiple }\end{array}$ \\
\hline $\begin{array}{c}\text { Nature/ } \\
\text { Quality } \\
\text { of product }\end{array}$ & $\begin{array}{c}\text { Own- } \\
\text { label/ } \\
\text { High }\end{array}$ & $\begin{array}{c}\text { Own- } \\
\text { label/ } \\
\text { Standard }\end{array}$ & $\begin{array}{c}\text { Standard } \\
\text { Single } \\
\text { supply } \\
\text { agreement }\end{array}$ & $\begin{array}{c}\text { Single } \\
\text { supply } \\
\text { agreement }\end{array}$ & $\begin{array}{c}\text { Single } \\
\text { supply } \\
\text { agreement }\end{array}$ \\
\hline \hline
\end{tabular}




\begin{tabular}{|l|l|l|l|l|l|l||}
\hline Unionised & Yes & No & No & Yes & Yes & Yes \\
\hline
\end{tabular}

Table 1: The Case Study Organisations

Qualitative research data was secured using semi-structured interviews with a number of respondents in each of the case-study organisations. Approximately 8-12 interviews with management respondents took place in each case-study, along with interviews with first-line managers, teamleaders and/or supervisors. Each interview took between 1-2 hours and was recorded. Between 4-6 focus groups of shop-floor operatives also took place in each organisation with a typical number of five employees in each group. Given the resource implications, the focus group respondents were selected by management.

\section{Constraining Dignity: The Tyranny of Routinized Low-Skilled Work?}

We highlighted in our previous engagement with Dignity at Work (Newsome, Thompson and Commander 2009) the nature of work within the food manufacturing companies conformed to classic assembly line production, characterised by low-skilled, low-paid, repetitive work with a highly gendered division of labour. Stir-fry had invested in technology to facilitate the large volumes of product that was required. From goods inward the product is routed along a series of conveyor belts to the picking tables, predominantly operated by women workers, and ultimately to packing areas. The constant and unremitting speed of the line resulted in work that was both physically arduous and mind numbingly dull. Unsurprisingly high levels of absenteeism exacerbated the intensity of work for operators left to cover for their absent colleagues. Asar lacking the resources invest in new technology safeguarded the necessary organisational flexibility by ensuring the factory operated $24 / 7$ production across three shifts. In Asar dedicated product lines cleaned, peeled, sliced, chopped or cut the product to the exact requirements and often contrary demands of multiple customers. Operators commented not only on the enervating monotony of the work, but also the insalubrious environment of the factory highlighting the noise, the smell and the often piercing cold. One focus group member argued

"We sometimes like to change our place because the job is boring and every day is the same and people are tired, it's not like physical it's emotionally. It's a job where you don't use your brain, it's more difficult emotionally than physically. And the cold, it is seriously cold in the sheds. You can't cover your hands up, you can't put the heater on because veg don't like heat." Operator Asar

Work organisation within Skin was similarly predicated upon assembly-line production based around a series of product lines. Skin had recently restructured and invested heavily in technology and automated further the product lines in order to facilitate the required organisational flexibility and responsiveness. Line operatives reported that far from the new technology eliminating the monotony of work and relieving boredom it had enabled a substantial increase in the intensity of work. Indeed as we indicated in our previous chapter, one line operator reported that she took travel sickness tablets to ameliorate the effects of motion sickness which she experienced working for long periods on the line. This restructuring also coincided with the switch from piece-rate, as a way of managing the effort bargain, to formalised hours seemingly to facilitate more consistent levels of performance. 
As one manager argued the rationale behind the new remuneration policy was to highlight to shopfloor workers, 'you're working at our pace not your pace, that was quite a big shift'.

Albeit within warehouses rather than the factory floor, the key similarities in terms of the organisation of work (and the denial of dignity) were evident in all of the distribution companies. Within the RDC goods are unloaded from grocery suppliers, stored and repackaged in the required quantities for their final destination to store. The organisation of work within the three warehouses revolves around a 'pick and pack' system. The ambient warehouse is divided into multi-tiered aisles with pick slots. 'Pickers' on trucks travel along the aisles picking the required pallets and items for delivery to store, once picked items are placed into 'cages' per store which are ultimately placed onto loading bays ready for delivery. Given the perishable nature of the product in the chilled warehouses, time pressures as such that products are simply unloaded and then immediately reloaded in the required amounts. Overall this is physically demanding, repetitive and labour intensive work process.

In Mirror operators contrasted the physically challenging nature of work, the penetrating monotony with their delight at the end of day when a shift was finished. One operator stated, 'you're knackered by the end of the shift but when you go out and you get the fresh air you feel amazing. You see people when you go out when they're finishing, all the smiles are back on their face." The opportunity to curtail the tedium of the working day through job rotation was often denied in Mirror with managers highlighting that ensuring the required pick rates took priority over relieving boredom. To expedite the movement of the product through the chilled warehouse in Mirror, pickers wore 'watch scanners' around their lower arm. These watch scanners allocate work, monitor levels of activity and track the movement of products (and labour) throughout the warehouse. For many Pickers, the prospect of working in the chill section and being forced to wear the scanner for the entire shift was viewed with dread and dismay. As one picker reported, "every morning you don't know which bit you go into. So it's like a dread of oh my God am I'm going to get the worst of it? You see other people, not just yourself, it's a lottery". Pickers in Manoeuvre and Signal reflected many of same concerns regarding the tedious, debilitating and intensified nature of work. Asked how they felt at the end of a working day the message was very clear, 'free'. In Manoeuvre the removal of tea breaks and cigarette breaks (a clear invasion of the porosity of the working day) exacerbated the supremacy of the pick rate and the organisational imperative of meeting required targets. As one picker reported, "you know you've got to pick that packet. And I know it sounds all robotic but it is. It is robotic. It sounds as if you're just a robot, but you are, really. Nobody even gets out for a fag. You used to be able to but they stopped it."

At this point in our previous chapter we posed the question, 'what then lies at the heart of these constraints on dignity and good work? Acknowledging that Hodson $(2001,76)$ was correct to note that food processing is one of the industries in which assembly work survives in a modern economy. Our argument was that this constraint on dignity in these factories was more than 'the tyranny of the assembly line'. We argued for the need to broaden our frame of reference to encompass the supply chain and the role of the customer. In essence our argument was that the dynamics of the labour process, embracing the conditions for dignity at work, could not be explained by containing our analysis to developments at the point of production. Indeed the role of the customer was crucial to understanding the denials of dignity within these food manufacturing companies. All of the organisations highlighted the power imbalance between themselves and their customers. The unrelenting pressure on price and price cutting as well as quality and service delivery, coupled with 
the often sporadic call for goods, impacted significantly upon these supply organisations. As such satisfying the demands of a seemingly insatiable customer clearly affected the conditions of work and employment. In this sense, the direct employer and its management, contra the implication of Hodson's framework, cannot guarantee dignity, whose primary source lies largely outside their control. Indeed we suggested that drawing on Bolton's (2007) distinctions of dignity - whilst the suppliers shape some of the conditions in work, the customer constrains the conditions at work. Yet the addition of the evidence from distribution and warehousing forces us to reflect upon this distinction and perhaps provide a more nuanced approach than a unilateral reference to the power of the 'customer' per se. Employment figures suggest that distribution and logistics is a key part of the UK economy in which numbers employed is increasing (ONS 2013). The nature of the relationship between the retailers and distribution companies provides further insights into the conditions that shape not only the capacity for dignity at work but also for an understanding of the dynamic of resistance and misbehaviour. In this sense the inclusion of distribution and warehousing provides the opportunity to explore the resilience of suppliers' capacity to shape conditions in work. The next section explores the nature of supply relations between both production and distribution companies and their dominant retailer customer and considers how this relationship impacts upon the capacity for dignity in work in particular issues relating to over-work and mismanagement are explored.

The food processing suppliers highlighted the unequal power dynamics between themselves and the retailers indicating that it manifest in a number of key supply pressures. All respondents referred to the on-going pressure to cut costs, reduce prices and absorb any additional costs into the business. In addition the highly unpredictable call for goods was also apparent. In order to accommodate these levels of unpredictability, working hours and patterns of workplace attendance had to be sufficiently flexible and immediately responsive to unexpected increases (or decreases) in demand. For managers in all of these organisations the constant juggling of matching staffing levels to scheduling requirements whilst simultaneous keeping costs down was a daily ritual that had to be carefully planned and executed. Referring to the need to fluctuate staffing levels the production manager in Skin argued,

"We'll try and encourage them to take some holidays or unpaid time off or we'll give them the option of staying at working and cleaning, for the rest of their shift. And most of them don't like to clean" Production manager Skin

The outcome for operators in all of the food processing organisations conforms closely to Hodson's denial of dignity through over-work. The extension of working-time through fluctuating shift patterns, long unpredictable hours and compulsory overtime became a key mechanism with which these organisation responded to unpredictability. Operators in Skin lamented the long shift patterns and highlighted particularly having to work at the weekend when all staff had to say on site until orders were complete. In Asar, operators similarly acknowledged the long working hours and highlighted the difficulties it created for child-care issues and work-life balance particularly when finish times (and sometimes start times if there was a rush order) were fluid and uncertain. One focus group member stated, "We seem to be here more than we are at home".

Whilst denial of dignity through over-work may have been evidence there was limited evidence within the food manufacturing of systematic mismanagement and/or abuse. There was pressure on performance but this had not extended to a systematic performance management regime which 
monitored individual activity. Indeed in attempting to increase performance levels these suppliers preserved some capacity to shape conditions in work. Supply organisations were however challenging reliance on traditional methods per se with the management of performance becoming visible and more formalised. Interviews were littered with references to the key performance indicators coupled with the introduction of a corresponding paraphernalia of 'efficiency boards', behavioural change, targets and monitoring. The depth and effectiveness of such measures however, remain uneven. In all of the case-study organisations within food processing limited attempts to establish visible and increasingly measurable levels of worker effort were apparent. However this monitoring of effort remained primarily with the work-group or the team. The further automation of production within Stir-Fry also gave management the opportunity to move towards the establishment of expected levels of effort for product lines. The suggestion here was that management and supervisors were aware of the output capacity of the machines and so now expected work effort to correspond. There was a shift to the use of manual and electronic boards linked to KPI. As an employee in a focus group at StirFry observed, 'so they're putting it on the board so all the lines see it and then they go we'll try and beat that, so they're trying to get you (to work harder...every hour they (line supervisor) come round and work out your efficiency and that'. Similarly in Skin recent investment in new technology gave management the opportunity to establish required levels of output and ensure they were clearly visible to operators. At Skin, they had just put up the first of a series of six plasma TVs. One manager argued,

"We're able now to track statistically what every line, or every machine line, produces in real time. So they'll see what the average number of bags per minute is for that machine, they'll see the actual target weights on it whether they are over or under. There's a massive amount of statistics available. And we're certainly noticed a difference since the staff have been able to visibly see that." (Skin Senior Manager 2)

However, across the companies, in order to secure these required levels of performance there is still also considerable dependence on direct supervision, 'going out on the line', exhortation and other forms of personal intervention - mediated, unsurprisingly by individual supervisor styles, some more reliant on coercive authority than others. These outcomes were indicated in the supervisor interviews, but also by employee focus groups. At Stir-Fry, when asked how management monitored their performance, the most common response was 'by coming to see us work', 'check on us'. The extent to which performance was secured in the plants through arbitrary managerial authority was also shown in the way that work effort is still regulated still through increasing line speed. Though operatives were aware of increased monitoring there was no evidence of internalisation of peer pressure per se. The growing levels of absenteeism within all of the organisations did however impact on those operators who turned up to work. A degree of disdain was frequent amongst supervisors and operatives concerning the effectiveness of new measures. A supervisor at Stir-Fry claimed that, 'we've got an efficiency board out there, see all the machines that are running every hour, I've blagged (the numbers) for the last four months and every manager goes out and they're looking, they don't know what they're looking at'.

In terms of support systems for the changes in work relations, cost pressures emanating from the supermarkets meant that a corresponding apparatus of incentive schemes capable of supporting and sustaining the performance management regimes were not forthcoming. At Stir-Fry recent initiatives 
have been undermined by an arbitrary and unpopular bonus system that management say is directed at both at enhancing performance and reducing absence.

".....because they keep on adding things on. It was meant to be an attendance bonus to start with and now it's just the least little thing, you've got an earring in, you've lost your bonus, you've got a necklace, lost your bonus" (Focus Group 1)

In the period immediately prior to site visits, only 24 out of 86 operatives received a bonus. However the bonus scheme was not viewed as representing systematic 'mismanagement' or abuse, on the contrary the common view (from operatives and supervisors) was that it was scorned, regarded as being 'a lot of shite'.

By contrast, managers in the distribution case-studies highlighted the fiercely competitive nature of the sector and emphasised the corresponding relentless pressure on cost reduction. For these third party companies the nature of the contractual relationship with their supermarket customers played a pivotal role in determining the conditions for dignity at work. Contracts were awarded for a three year periods, as a result ensuring the renewal of the contract was a key management objective. The contractual relationship between all of these organisations and their retailer customer was predicated upon open book contracts and a series of rigorous and tightly monitored key performance indicators (KPI) to run the site and ensure delivery to store. Given the nature of the contract many of the KPI related to labour costs notably; productivity levels; absence levels; and overall staffing levels. All of the organisations were accountable for delivering on these KPI and subject at least weekly updates of progress. Failure to meet the KPI would be immediately challenged and resulted in either penalties applied to the contract and/or would jeopardize the possibility of contractual renewal. In addition to the stringent KPI requirements the pressure to deliver on-going cost reduction was evident in all organisations. In Signal the site manager highlighting the seemingly insatiable pressure from the supermarket for cost reduction. He stated, 'the customer do that all the time, they're always asking us right okay where can we save money? It's our job to go and see where we can cut. What we can do is make them pick quicker, so that we're getting more cases per hour.' As a result of this contractual relationship the focus on individual performance within all of the distribution companies is insistent.

Correspondingly the conditions for the denial of dignity at work through mismanagement and abuse were apparent. To establish 'norms' in the required rates of effort all of the organisations employed external consultants to undertake time and motion studies. Performance, it seemed, could only be managed if required rates of efforts could be stipulated, rendered transparent and ultimately measured. Within Mirror, one KPI related to the overall warehouse rate which was calculated on productivity levels within the organisation. One manager argued, 'We've had a time and motion study done in here so we know how much a person can bring in an hour and we just multiply that by their hours with their work on that job' The site manager echoed this view highlighting that securing the required norms of individuals daily effort enabled the organisation to satisfy the demands of their supermarket client. The situation was echoed in Manoeuvre with attempts to secure greater levels of performance predicated upon securing greater levels of transparency and ultimately measurability were regarded as a key priority. Once again, time and motion studies provided the opportunity for managers to close down any indeterminacy, invade porosity and establish required norms of worker effort. From this study the required daily rate was established indicating what the expected pick rate would be for a working day. 
Within Signal the retail customer directly used the results of the time and motion study to dictate the required hourly pick rate upon the organisations. The imposition by the customer of the required hourly levels of effort created high levels of pressure in the organisation to ensure this rate was maintained. One picker argued, "Its pressure because I think it is hard work because it's supposed to be physically hard work, but the second thing is pressure on the target here. Here you must doing 150 on the hour, you must be running. There's a lot of folk that don't take their full break as well because they get pressured in to hitting the target. We're meant to get half an hour break, but there's a lot of folk maybe only take maybe 15 or 20 minutes." Having established the required levels of performance management within these distribution organisations focused attention on ensuring these rates were delivered to the customer. However attempts to deliver additional remuneration to reflect this additional effort proved to be problematic. Within Signal and Manoeuvre any attempt to incentivise required performance levels had recently been removed. HR managers within both organisations argued that the removal of incentive payments were part of an overall strategy to review all terms and conditions and eliminate any unnecessary cost to the business. Within Signal the site manager acknowledged the difficulties this presented in terms of managing performance levels, relating this specifically to the exacting requirements of the supermarket to secure cost savings.

As a result of the absence of incentive payments to manage the effort-bargain, managers within all of the distribution companies turned to more direct methods of control to ensure performance levels were delivered. As a result, and to varying degrees, all of the companies implemented performance management regimes comprising of tighter surveillance and monitoring procedures, close and direct supervision and within Signal and Manoeuvre a draconian disciplinary regime. If the required levels of performance could not be incentivised, they needed to be 'managed' to ensure the required levels of effort. Within Signal and Manoeuvre the response was unforgiving regime of morning team briefing sessions, often hourly monitoring to ensure required levels were reached and a draconian disciplinary policy designed to reprimand anyone failing to meet $100 \%$ of the required rate. Pickers in Signal highlighted that these meeting were hostile and often aggressive, with supervisors often adopting a belligerent attitude. One picker argued,

"You're under pressure straight away, after the briefing you get the morning. Whatever he says that's you under pressure before you walk out the door to start your work. He says you're not doing enough work, try and get more out, do a lot better and all that. I just ignore it now, it doesn't bother me but a lot of people take it to heart. One of the managers a while ago said in the morning briefing 'if you don't do your rate there'll be no job in here for you'. A few guys complained about him and he wasn't allowed to do that again. A few guys complained he was bullying and his manager had a talk to him because his attitude was stinking."

In attempt to ensure the maximum amount of productive labour time in both Signal and Manoeuvre attempts to removal any obstacle to extract of effort and invade the porosity of the working day were also evident. Within Manoeuvre part of the overall review of terms and conditions emanating from the cost cutting demands of the customer, tea/comfort breaks had been removed. Pickers within Manoeuvre commented on the health and safety impact of the removal of comfort breaks. They highlighted that often people had previously worked through their breaks if they knew their daily rate was unlikely to be achieve. One picker argued, 'you can imagine if you're under performing the temptation is to push the boundaries and again I don't think that's good for the individual and it certainly isn't good for the employer, longer term, because if there is an accident you know there's a potential for a fatality there.' 
Failure to meet the required standard of performance within Signal and Manoeuvre monitored on a daily basis was met with immediate remedial action. Pickers highlighted the 'strict' nature of the regime. Failure to meet the required standard would be met with an immediate 'informal' conversation with supervisor. Within Signal this prompted a quality of work letter which would be sent to the Picker's home outlining where and how their performance had been deficient. Only three 'Quality of Work' letters would be tolerated in a six month period. A fourth letter within the period would be escalated to formal disciplinary action. Within Manoeuvre a similar procedure was in place whereby failure to meet the required standards was meet with a warning procedure, 'a 13 weeker' if performance levels were not meet during this thirteen week period, pickers would be placed on a ' 26 weeker'. Again any further failure to meet the required levels of performance during this period would be meet with formal action.

This discussion has raised issues about managerial agency and the role of the retailers in shaping the conditions for dignity at work. The next section explores the role of worker agency in safeguarding dignity.

\section{Employee Responses: safeguarding dignity?}

Despite the constraints on workplace dignity within the all of the case-study organisation from both immediate employers and the dominant customer(s) attempts to safeguard dignity were evident. Employees employed a variety of strategies of reshaping, recasting and resisting the requirements of the working day. These efforts at reshaping the requirements of production were based around escaping and 'separating' from the pressure and the monotony of the work process to more systematic forms of resistance, particularly in distribution and warehousing.

The opportunity to safeguard dignity through social aspects of work and relations with co-workers was more easily available for workers in food production. These relations with co-workers however constrained by the requirements of production, provided the opportunity for workers to separate themselves from the monotony of their work. Despite the production pressures the opportunity to talk, share concerns and exert some control over the speed of work was evident. Within Stir-fry operators highlighted that the opportunity to engage with their co-workers provided the opportunity to cope with pressurised production requirements. One operator highlighted, "Everybody's got problems, we just share them about, just takes a load off your mind, you tell somebody else." Within Asar, women workers mindful that their physical immobility was curtailed by the requirements of the assembly-line, highlighted that they would sing amongst themselves in order to get through the day and cope with the monotony. Other employees within Asar highlighted that the capacity to vary the pace of work in order to be able to 'take it easier' was still available.

Indeed, some notion of worker unity was often based upon a common appreciation of the difficulties of meeting production requirements, coping with the pressure of work and having to deal with what was often regarded as overzealous supervisors and first-line managers. The support from co-workers within all the organisations meant that despite the attacks on their dignity at work still took some pride in their work and gained some level of satisfaction from meeting the competing demands of customers. Indeed there was some recognition that satisfying the supermarket customer(s) was important, the suggestion being 'we all want our jobs.' However all of the organisations reported that high levels of absenteeism and non-attendance. Indeed in Stir-Fry the introduction of a draconian attendance policy based upon a bonus scheme seemed particularly effective at exacerbating levels of non-attendance and dis-engagement. 
Indeed an additional outcome of pressurized, low paid and low skilled work was that management in these organisations was finding it difficult to ensure levels of workplace attendance and recruit local labour. One manager in Asar highlighted, "I've seen people come in in the morning at eight o'clock and go home at half past ten because they just can't handle the job, they just don't like it, the smell, the cold, various factors." Indeed all of the organisations were increasingly turning to the recruitment of migrant labour as a way of dealing with the problem of staffing the organisations. However managers in Stir-Fry particularly highlighted that the appetite for over-time and extra work amongst migrant workers was diminishing and that absence problems were prevalent amongst this group of workers. One manager reported,

"When the foreign labour came they were here all the time because they were willing to do all overtime but now, I don't know if it's because they've got their families or they're settled but we can't get them to do the overtime either, they're the first out the door. Again I can see the pattern like a lot of sick days with them as well now." Manager Stir-Fry

In distribution and warehousing, despite the aforementioned denials on dignity, emanating from the requirements of the customer the capacity and the opportunity for the safeguarding of dignity was evident. Employee initiated responses reflect both individual and collective forms of misbehaviour and resistance. However it was clear in these organisation that the capacity to undertake reshape and recast the requirements of work on an informal basis were increasingly curtailed. The performance management techniques, close surveillance and high pick rates meant that the capacity to control the speed of work had been reduced. As such many of Pickers attempts to recast the requirements of the work process where based around 'surviving' rather than 'escape' per se. In Manoeuvre one picker highlighted that "There's no way you can just stand, and talk for half an hour. You can't do that because then you're chasing all day. It's just a mode you go into and you know you've got a target in your head that you've got to pick, or try and pick." Pickers in Mirror similarly reported on the limited capacity to re-shape the requirements of work and that they had to try and cope with the pressure in whatever why possible. One picker stated, "You struggle, but to make money you've just got to switch off if possible. You've just to think of your home life and why you're doing it. Think what you've got coming up and look forward to things."

More direct forms of resistance and misbehaviour were also evident. The issue of grazing was highlighted as a perpetual problem in distribution and warehousing. Grazing takes place when employees help themselves to, and consume the product. Pickers in all of the organisations made a distinction between grazing, regarding this a relatively harmless 'pilfering' which 'helps your stress levels' and theft. The suggestion was that it was only if the product was taken out of the door of the warehouse, could it strictly be regarded as theft. One picker argued, 'people will go round getting things for their cup of tea, maybe a packet of biscuits are burst open but I don't think anybody actually steals stock, taking it out the door.' In the aisles within all organisations evidence of grazing was apparent with empty packets and opened cans of drink being relatively commonplace. Pickers in Mirror reported, 'The funniest one I heard, it was only about six months ago, I can't remember the Polish guy's name he was driving down the aisle, smoking a fag and drinking the miniatures of Scottish whisky."

Managers within all of the organisations reported that grazing and theft was an on-going problem that required constant surveillance. Mirror operated a system of CCTV monitoring and random searches. 
At the end of every shift as employees left the organisation they were required to press a button which indicated whether you were required to be searched. In addition locker searches took place. Nevertheless despite these measures management in the organisation was aware of the problem persisting. The HR manager argued, 'I dismissed a guy for stealing a packet of butter ...no sorry I'm lying a packet of butter and a bottle of vodka, I don't know what he was up to? Within Signal a third party Security Company was employed specifically by the Supermarket to 'protect their stock'. Uniformed security guards patrolled the aisles of the warehouse, undertook spot checks and generally provided an additional level of surveillance. Nevertheless grazing was still regarded as a perpetual problem which required a degree of vigilance on behalf of management. The HR manager reported, 'which is why you have to have a strong policy and why it has to be transparent to everybody because at the end of the day, this site and everything that's on it including all of the stock belongs to Supermarket Y. It's the security teams' job to make that secure and to protect that.' Mangers in Signal similarly reported that dealing with grazing was part of a daily routine. One supervisor stated,

“Warehouses are big, they're big big places and they're hard to monitor. We try and highlight these areas, we try and monitor these areas, but obviously we can't have a camera up every aisle so we need to try and kind of...but the guys get wise to it as well, they'll take the case from that pick slot, put it on their truck and go round to another aisle where its quieter. Today its Jaffa cakes, red bull and caramel cupcakes that somebody's eaten. The Jaffa cake is regular one, it's the Jaffa cake minis which are dead easy for them to put in their pockets I think and the red bull. Quite ironically is an energy drink [laughs]." Supervisor Signal

\section{Reflections and conclusions}

The case studies discussed in this paper paint a fairly bleak picture of factory life at the end of the supermarket supply chain and that pessimism is matched in a recent wide-ranging study of food processing in five European countries (Grunert, James and Moss 2008). If there is little sign of the kind of good work that might confer a degree of dignity, there are, conversely, few glimpses of the 'good worker': the employees who are committed to or compliant with the factory regime. This is, arguably, because there is little to buy into. Whilst these are workplaces with cultures, they do not have cultureled management and there is little to engage hearts and minds. This is not to say that the workforces resist in any significant way - the imbalance of power resources induces disaffection, but little beyond.

Returning the kind of criteria set out by Hodson and colleagues, to what extent are the conditions for denial or destruction of dignity present? These are workplaces with high levels of work intensity and 'overwork', filtered through assembly lines subject to largely unilateral technical controls. Though assembly work is seldom pleasant, the nature of the product in many of these instances adds a further dimension of hazardous work environments through extremes of temperatures, smells and noise levels. It could be argued that these conditions are of long-standing in the food processing sector. Think of Upton Sinclair's description of Chicago meat packing plants in The Jungle.

However, in a crucial respect, the circumstances differ sharply from Hodson's argument. Management, authority and work organisation in these plants is not, by and large, 'abusive', chaotic', or 'anomic'. Such terminology creates the unavoidable impression of pre-rational workplaces based on arbitrary, personal power. In our cases, the plants are not much 'mis-managed' as managed rationally according direct and indirect pressures exerted through supply chain power dynamics. The ethnographic dataset used by Hodson and colleagues is based on a single organisation frame and the 
customer eppears marginally and only in terms of horizontal rather than vertical relations. Yet, in our cases, much of the distinctive and destructive attacks on dignity only make sense in that wider context. Work intensity becomes work intensification as lines are speeded up and work stretched out to meet cost cutting supermarket or other purchaser requirements. Indirect pressures of this kind are likely to have negative consequences for occupational ill health in food processing (Lloyd 2008). But it is in the sphere of time that the most significant effects take place. Dignity comes, in part from a regulated effort bargain that generates a degree of consistency and stability. What we have much of the time in these cases is a form of hyper-flexibility in which the worker's tasks and times are at the whim of the employer, though, in fact, the employer is really dancing to the customer's tune. In this sense, the direct employer and its management, contra the implication of Hodson's framework, cannot guarantee dignity, whose primary source lies largely outside their control. Or put another way and returning to Bolton's (2007) distinctions - whilst the suppliers shape some of the conditions in work, the customer constrains the conditions at work. Such outcomes are exacerbated in product lines characterised by perishability as at Stir-fry. The negative consequences for dignity are seen not just in the work itself, but in the impossibility of an adequate work-life balance, whether through compulsory overtime or compulsory availability.

Add reference to incivilities and link to horizontal conflicts below

There were claims from some employees (at Stir Fry) that migrant workers had been brought into weaken unionisation efforts, but this is almost certainly confusing intent with outcome. Even that judgement is too stark to grasp the complexity of the impact of migrant labour. On the one hand, the willingness to work hard or harder than their local counterparts is clearly a source of dignity and pride to many Polish and other migrant workers. And this, in turn, supports the perceptions of managers about this (extra) willingness to work. On the other hand, there appears to be evidence that disaffection and misbehaviour may be more a function of time and experience than ethnicity. Similarly there is no evidence that migrant workers are anti-union or less willing to join. What does appear to be the case, however, is that the dignity and social solidarity that workers traditionally seek through peer networks (co-workers in Hodson's terms) is weakened, at least in the short term, through greater workforce heterogeneity. Voices are raised, but multiply as experiences and mechanisms for expressing it vary. Such fragmentation also has potentially negative implications for positive citizenship behaviours that rely, in part, on shared norms concerning appropriate levels and types of effort.

Factory work need not be low waged or low skilled and, as Bolton argues there can be dignity in and at work. Neither is present here to any significant degree here. The primary reason is that supermarkets have engineered a double transfer of risk: first from them to the owners and managers of the supply firms themselves, then from them to the labour force, which is in itself fractured on gender and ethnic lines. In the absence of formal, collective organisation, the cases reveal the normal variety of informal actions from group-based output norms, to minor acts of misbehaviour such as absenteeism and re-appropriation of time. But coping strategies and disengagement are far more typical responses than any form of resistance. In the absence of better regulated labour markets, innovation or greater independence in the product market by suppliers, or successful unionisation drives, these circumstances are unlikely to alter. 
What promotes and prevents dignity is not frozen in time, but is constantly being remade as forms of competition, ownership, worker organisation and social norms change. Hodson's framework for addressing issues of dignity and to a lesser extent resistance, remain an indispensable but incomplete entry point for understanding theits dynamics.

\section{References}

Bolton, S. (2007) Dimemsions of Dignity at Work, London, Butterworth Heineman.

Casey, C. (1995) Work, Self and Society: After Industrialism. London: Routledge

Contu, A. (2008) 'Decaf Resistance: On Misbehavior, Cynicism, and Desire in Liberal Workplaces', Management Communication Quarterly 21: 364-379.

Fleming, P. and Spicer, A. (2008) 'Beyond Power and Resistance: New Approaches to Organizational Politics', Management Communication Quarterly 21: 301-309.

Gabriel, Y. (2008) 'Spectacles of Resistance and Resistance of Spectacles', in Management Communication Quarterly 21: 310-326.

Grunnert, K., James, S. and Moss, P. (2008) Chocolate Chicken: bittersweet implications for low wage work in the food processing industry, Report to Russell Sage Foundation Conference on Low Waged Work, Paris, 1-3 February.

Hodson, R. (2001) Dignity at Work, Cambridge: Cambridge University Press.

Leidner, R. (2006) 'Identity and Work,' in Social Theory at Work, M. Korczynski, R. Hodson and P. Edwards (eds.) Oxford: OUP. 424-463

Milkman, R. (1997) Farewell to the Factory: Auto Workers in the Twentieth Century Berkeley: University of California Press.

Lloyd, C. (forthcoming, 2009) 'Too much pressure? Retailer power and occupational health and safety in the food processing industry', forthcoming in Work, Employment and Society.

O'Doherty, D. and Willmott. H.(2001) 'Debating Labour Process Theory: The Issue of Subjectivity and the Relevance of Poststructuralism' Sociology, 35/2, 457-476.

Rayner, Ch, and K. Mclvor. "Research report on the dignity at work project." Report prepared for Amicus and DTI (2008).

Roscigno, Vincent J., Randy Hodson, and Steven H. Lopez. "Workplace incivilities: the role of interest conflicts, social closure and organizational chaos." Work, Employment \& Society 23.4 (2009): 747773.

Roscigno, Vincent J., and Randy Hodson. "The organizational and social foundations of worker resistance." American Sociological Review 69.1 (2004): 14-39. 
Sayer, A. (2007b) 'What Dignity at Work Means', in Bolton, S. C. (ed.) Dimensions of. Dignity at Work, London: Butterworth Heineman.

Thompson, P. and Ackroyd, S. (1995) 'All Quiet on the Workplace Front? A Critique of Recent Trends in British Industrial Sociology', Sociology, 29/4, 1-19.

Thompson, P., and Newsome, K. (2004) 'Labour Process Theory, Work and the Employment Relation' in Kaufman, B.E. (ed.) Theoretical Perspectives on Work and the Employment Relationship. Cornell: Cornell University Press. 